Florida International University

FIU Digital Commons

Coronavirus Research at FIU

$5-29-2020$

Potential RNA-dependent RNA polymerase inhibitors as

prospective therapeutics against SARS-CoV-2

Rudramani Pokhrel

Prem Chapagain

Jessica Siltberg-Liberles

Follow this and additional works at: https://digitalcommons.fiu.edu/covid-19_research

Part of the Medicine and Health Sciences Commons

This work is brought to you for free and open access by FIU Digital Commons. It has been accepted for inclusion in Coronavirus Research at FIU by an authorized administrator of FIU Digital Commons. For more information, please contact dcc@fiu.edu. 


\title{
Predictive modelling of COVID-19 confirmed cases in Nigeria
}

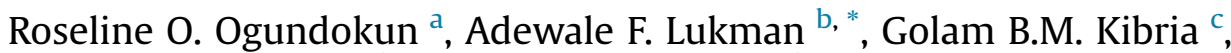 \\ Joseph B. Awotunde ${ }^{\mathrm{d}}$, Benedita B. Aladeitan ${ }^{\mathrm{b}}$
}

${ }^{a}$ Department of Computer Science, Landmark University Omu Aran, Nigeria

${ }^{\mathrm{b}}$ Department of Physical Sciences, Landmark University Omu Aran, Nigeria

${ }^{\mathrm{c}}$ Department of Mathematics and Statistics, Florida International University, Florida, USA

${ }^{\mathrm{d}}$ Department of Computer Science, University of Ilorin, Ilorin, Nigeria

\section{A R T I C L E I N F O}

\section{Article history:}

Received 24 June 2020

Received in revised form 27 July 2020

Accepted 7 August 2020

Available online 15 August 2020

Handling editor: Dr. J Wu

\section{Keywords:}

COVID-19

Pandemic

Linear regression model

Prediction

Ordinary least squares estimator

Diagnostic checks

\begin{abstract}
A B S T R A C T
The coronavirus outbreak is the most notable world crisis since the Second World War. The pandemic that originated from Wuhan, China in late 2019 has affected all the nations of the world and triggered a global economic crisis whose impact will be felt for years to come. This necessitates the need to monitor and predict COVID-19 prevalence for adequate control. The linear regression models are prominent tools in predicting the impact of certain factors on COVID-19 outbreak and taking the necessary measures to respond to this crisis. The data was extracted from the NCDC website and spanned from March 31, 2020 to May 29, 2020. In this study, we adopted the ordinary least squares estimator to measure the impact of travelling history and contacts on the spread of COVID-19 in Nigeria and made a prediction. The model was conducted before and after travel restriction was enforced by the Federal government of Nigeria. The fitted model fitted well to the dataset and was free of any violation based on the diagnostic checks conducted. The results show that the government made a right decision in enforcing travelling restriction because we observed that travelling history and contacts made increases the chances of people being infected with COVID-19 by $85 \%$ and $88 \%$ respectively. This prediction of COVID-19 shows that the government should ensure that most travelling agency should have better precautions and preparations in place before re-opening.

(๑) 2020 The Authors. Production and hosting by Elsevier B.V. on behalf of KeAi Communications Co., Ltd. This is an open access article under the CC BY-NC-ND license (http://creativecommons.org/licenses/by-nc-nd/4.0/).
\end{abstract}

\section{Introduction}

COVID19 is a new pandemic triggered by extreme acute respiratory coronavirus syndrome 2 (SARS-CoV-2) and spreads rapidly from person to person (Ceylan, 2020). This pandemic is the most notable world crisis since the Second World War. According to literature, the outbreak originated from Wuhan, China, in late 2019 and has triggered a global economic crisis whose impact will be felt for years to come (Ayinde et al., 2020; WHO, 2020). On January 30, 2020, the World Health Organization (WHO) declared the outbreak as a Public Health Emergency of International concern (International Health

\footnotetext{
* Corresponding author.

E-mail addresses: Ogundokun.roseline@lmu.edu.ng (R.O. Ogundokun), adewale.folaranmi@lmu.edu.ng (A.F. Lukman), kibriag@fiu.edu (G.B.M. Kibria), awotunde.jb@unilorin.edu.ng (J.B. Awotunde), aladeitan.benedicta@Imu.edu.ng (B.B. Aladeitan).
}

Peer review under responsibility of KeAi Communications Co., Ltd. 
Regulations, 2020; World Health Organization 2020). There has been about 8, 061, 550 COVID-19 incidents registered in over 200 republics and regions which had brought about around 440,290 demises as of June 18, 2020 (NCDC Nigeria, 2020 ). The disease is mainly transmitted through nearby interaction, mostly by tiny beads formed through coughing, sneezing, or speaking (Control and Prevention, 2020; European Centre for Disease Prevention and Control, 2020; World Health Organization, 2020; Centers for Disease). Also, individuals could often turn out to be contaminated through being in contact with an affected exterior (World Health Organization, 2020; Centers for Disease Control and Prevention, 2020).

Nigeria announced the Sub-Sahara Africa's first confirmed case of COVID-19 disease on Friday January 28, 2020 at around 1 am. This confirmation led to the activation of the country's National Coronavirus Emergency Operation centre (Adepoju, 2020). According to the Nigeria Centre for Disease Control (NCDC), COVID-19 has presently infected 36 states in Nigeria. As at June 18, 2020 the number of samples tested in Nigeria is 106, 006 out of which 17, 735 of them is confirmed positive, 11, 299 of the individuals are active ones, discharged cases is 5967 and demise is 469 individuals (NCDC Nigeria, 2020; Wikipedia, 2020).

Different models have been used in recent studies to predict incidence, prevalence and mortality rate of COVID-19. Li et al. (2020), for instance, built a method for forecasting the ongoing trend with data-driven analysis and estimating the COVID-19 outburst size in China. Fanelli and Piazza (2020) studied the COVID-19 pandemic temporal dynamics in mainland China, Italy and France. Roda et al. (2020) correlated the standard SIR and SEIR frameworks to model COVID-19 in Wuhan China. Wei et al. (2016) forecast the national and global spread of COVID-19 to determine the impact of the metropolitan-wide isolation of Wuhan and its neighbours. Al-qaness et al. (2020) enhanced the Adaptive Neuro-Fuzzy Inference System (ANFIS) by implementing an Enhanced Flower Pollination Algorithm utilizing the Salp Swarm Algorithm to evaluate the number of confirmed COVID-19 crisis in China. Anastassopoulou et al. (2020) research on the assessment of the severe epidemiological constraints as well as the demonstrating and forecasting the transmission of the COVID-19 pandemic in Hubei, China. Wang et al. (2020) established the Patient Information Based Algorithm for evaluating the demise rate of COVID-19 in real-time by utilizing openly accessible datasets.

Recently, statistical and time series model has also been introduced to model and predict the prevalence of this pandemic. Ayinde et al. (2020) subjected the COVID-19 cumulative confirmed cases in Nigeria to some curve statistical estimation models. Ghosal et al. (2020) employed the linear regression analysis to predict the number of deaths in India due to SARSCoV-2. Ceylan (2020) applied the auto-regressive integrated moving average (ARIMA) model to predict the prevalence of COVID-19 in Italy, Spain, and France.

This study aims to predict the prevalence of COVID-19 in Nigeria using a linear regression model. Also, to measure the impact of travelling history and contact on COVID-19 confirmed cases.

\section{Materials and methods}

We consider the general linear regression model:

$$
y=X \beta+\varepsilon
$$

where $y$ is an $n \times 1$ vector of response variable, $X$ is a known $n \times p$ full rank matrix of predictor or explanatory variables, $\beta$ is an $p \times 1$ vector of unknown regression parameters, $\varepsilon$ is an $n \times 1$ vector of errors such that $E(\varepsilon)=0$ and $V(\varepsilon)=\sigma^{2} I_{n}, I_{n}$ is an $n \times n$ identity matrix. The ordinary least squares estimator (OLS) of $\beta$ in (2.1) is defined as:

$$
\widehat{\beta}=(S)^{-1} X^{\prime} y
$$

where $S=X^{\prime} X$ is the design matrix. The performance of the estimator is best when there is no violation of any of the assumptions of classical linear regression model (Ayinde et al., 2018; Lukman et al., 2019). The assumptions include: nonnormality of the error term, uncorrelated error term, orthogonality of the predictor variables and others (Gujarati, 1995). In this study, data was extracted from the NCDC website https://ncdc.gov.ng/. The dataset was collected in an excel file and analysed with the GRETL software. The variables of interest include confirmed cases as the response variable, travelling history and contact as the regressors. The regression model in this study is as follows:

$$
y=\beta_{0}+\beta_{1} X_{1}+\beta_{2} X_{2}+\varepsilon_{i}
$$

where $y$ represents COVID-19 confirmed cases in Nigeria, $X_{1}$ represents the travelling history before and after lockdown and $X_{2}$ represents the number of contacts made by a COVID-19 patient. We conducted a correlation analysis to investigate the relationship between the regressors and the response variable.

The results in Table 1 shows that a strong positive relationship exists between the confirmed cases and contact. A low and moderately high positive relationship exists between confirmed cases and travelling history; contact and travelling history, respectively. The descriptive statistics of the variables of interest are available in Table 2 . On average, there are 803 contacts made daily by COVID-19 infected patients. Of all the COVID-19 infected patients, about 191 of them have travelling history daily. The minimum and the maximum number of contacts made for the days covered in this study are 18 and 2407 , respectively. A regression analysis was carried out to examine the relationship of the response variable (confirmed cases) with 
Table 1

Correlation matrix of the variables of interest.

\begin{tabular}{lll}
\hline confirmed cases & travelling history & contact \\
\hline confirmed cases & 0.4771 & 0.9955 \\
travelling history & & 0.5259 \\
Contact & & \\
\hline
\end{tabular}

Table 2

Summary statistics of the variables.

\begin{tabular}{lllll}
\hline Variable & Mean & Std. Dev & Min & \\
\hline Travel history & 191.13 & 38.564 & 83 & \\
Contact & 803.30 & 708.01 & 18 & 210 \\
\hline
\end{tabular}

the regressors (Travel history and number of contacts). We adopt the Ordinary Least Squares (OLS) estimator in (2.2) to estimate the parameters of the regression model in (2.3). The result of the regression analysis using ordinary least squares estimator is displayed in Table 3.

The Jarque-Bera test in Table 3 shows that the error term is normally distributed. From Table 3, we observed that the contact have a positive influence on COVID-19 confirmed cases as expected while travelling history have a negative impact as

Table 3

The multiple regression analysis output after travelling lockdown.

\begin{tabular}{|c|c|c|c|c|c|c|c|c|}
\hline Variable & Coefficient & S.E & t-stat & P-Value & Diagnostic test & & & \\
\hline Intercept & 542.18 & 158.346 & 3.424 & 0.0012 & $\mathrm{R}^{2}$ & 0.9941 & Durbin-Watson test & $0.5431(0.0000)$ \\
\hline Travel history & -4.8309 & 0.9036 & -5.346 & $<0.00001$ & F-test & $4771.52(0.0000)$ & White test & $11.3410(0.045)$ \\
\hline Contact & 4.2217 & 0.0492 & 85.7753 & $<0.0001$ & Jarque Bera-test & $1.1261(0.5695)$ & VIF & 1.382 \\
\hline
\end{tabular}

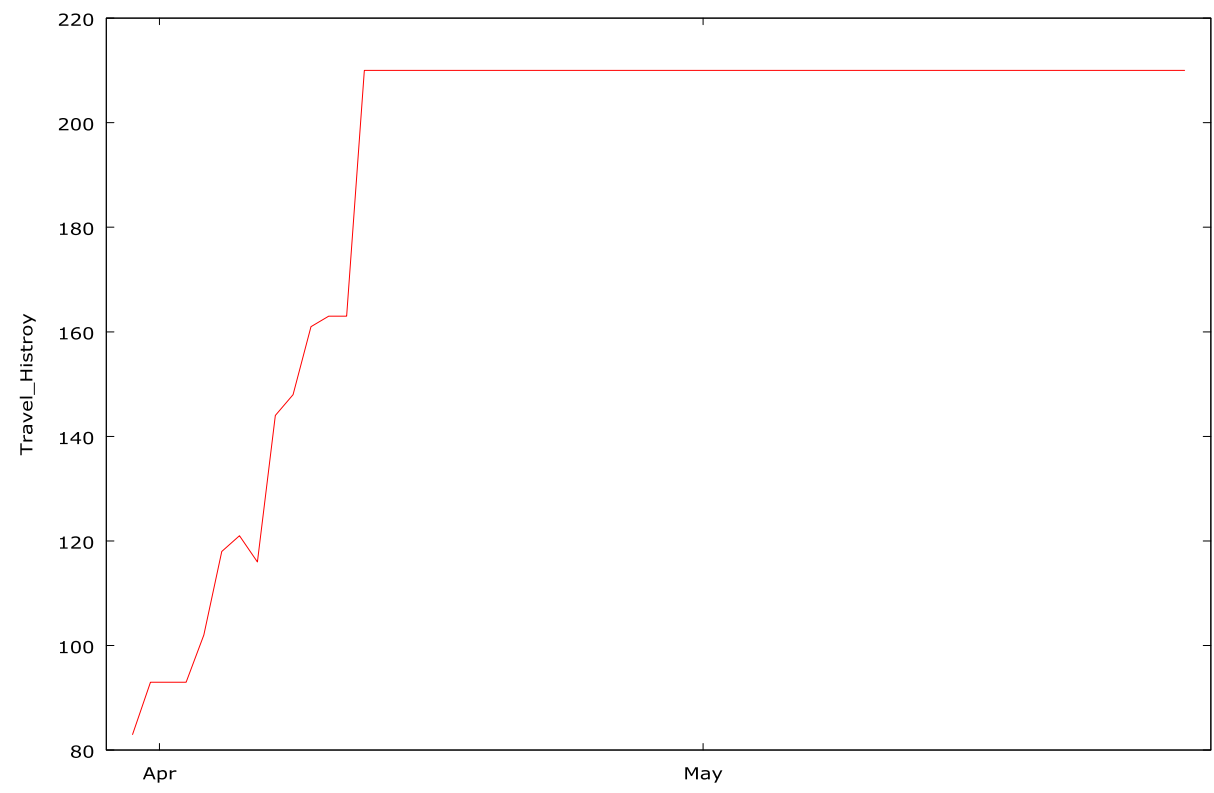

Fig. 1. Showing daily effects of travel history on confirmed cases.

Table 4

Multiple regression analysis output before travelling lockdown.

\begin{tabular}{|c|c|c|c|c|c|c|c|c|}
\hline Variable & Coefficient & S.E & t-stat & P-Value & Diagnostic test & & & \\
\hline Intercept & 79.8934 & 15.2784 & 5.2292 & 0.00028 & $\mathrm{R}^{2}$ & 0.9646 & Durbin-Watson test & $1.5213(0.0848)$ \\
\hline Travel history & 0.8542 & 0.196605 & 4.3449 & 0.00117 & F-test & 150.0757 & White test & $8.7344(0.1201)$ \\
\hline Contact & 0.8762 & 0.202713 & 4.3225 & 0.00121 & Jarque Bera-test & $0.7836(0.6758)$ & VIF & 4.262 \\
\hline
\end{tabular}




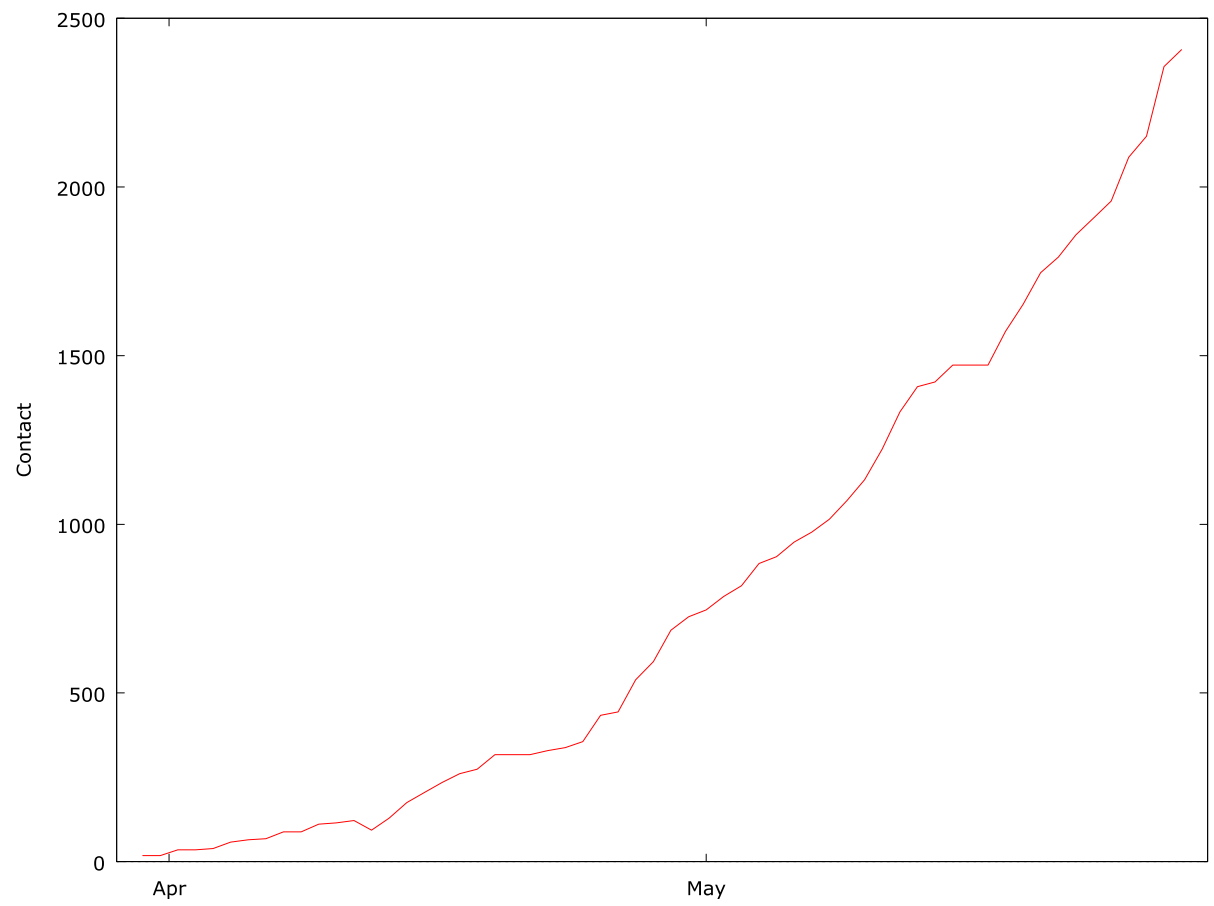

Fig. 2. Showing daily effects of increase in contact rate on confirmed cases.

expected. The introduction of travelling lockdown leads to about 4.8\% reduction in the number of COVID-19 cases that could have happened. We observed that the dataset on travelling history became constant from April 14, 2020, when the travelling restriction was placed on both local and international flights by the Federal government of Nigeria. We illustrate this graphically in Fig. 1. Fig. 1 shows that there is a daily rise in travel history up to the point where a ban was placed on all travels which are responsible for the stability seen in travel history over a period. Fig. 2 shows that there is an exponential rise in the

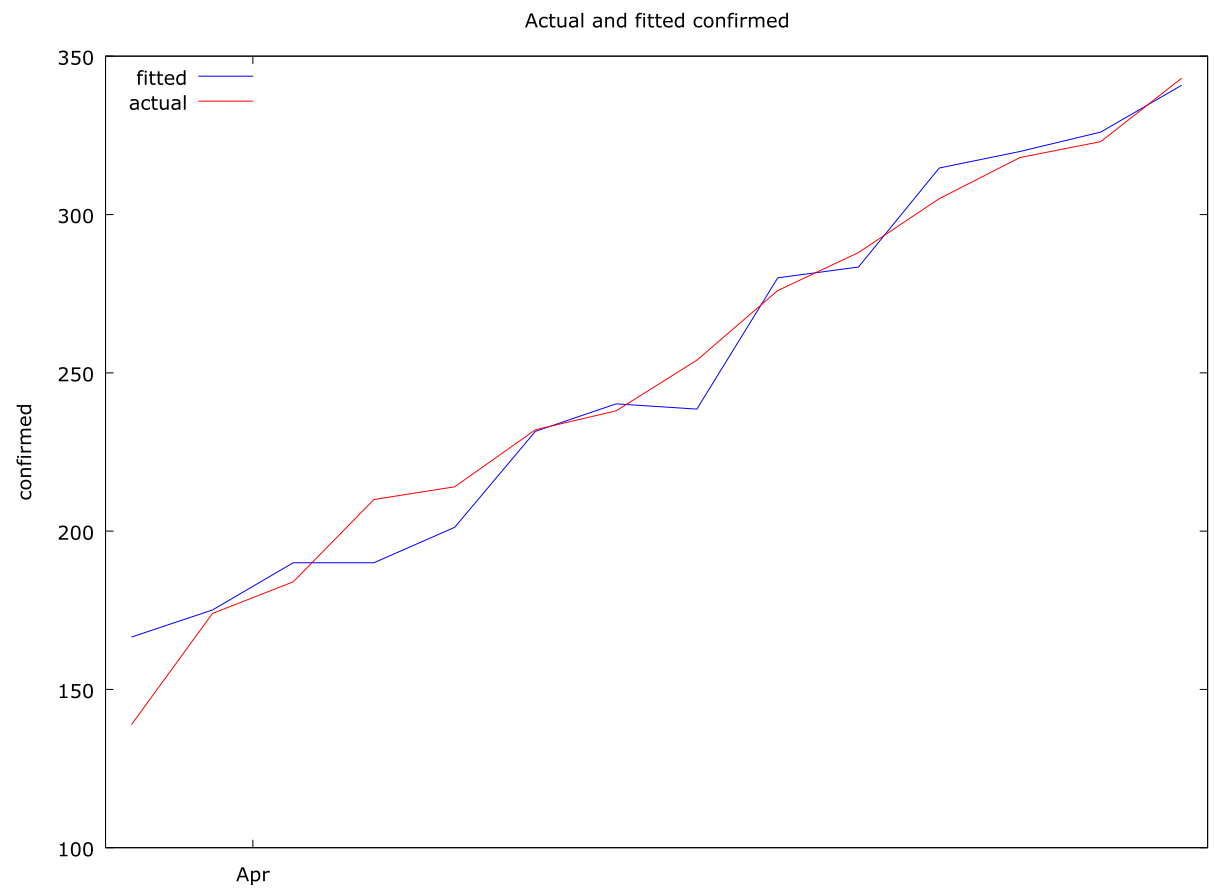

Fig. 3. Actual and fitted values of COVID-19 confirmed cases. 
Table 5

The actual values and the prediction.

\begin{tabular}{llll}
\hline Date & confirmed & prediction & $95 \%$ interval \\
\hline April 5, 2020 & 232 & 231.51 & $202.66-260.37$ \\
April 6, 2020 & 238 & 240.21 & $211.35-269.07$ \\
April 7, 2020 & 254 & 238.57 & $209.26-267.88$ \\
April 8, 2020 & 276 & 280.01 & $250.90-309.12$ \\
April 9, 2020 & 288 & 283.43 & $254.35-312.51$ \\
April 10, 2020 & 305 & 314.69 & $284.32-345.05$ \\
April 11, 2020 & 318 & 319.9 & $289.19-350.61$ \\
April 12, 2020 & 323 & 326.03 & $294.35-357.72$ \\
April 13, 2020 & 343 & 340.77 & $302.12-379.42$ \\
\hline
\end{tabular}

number of people contaccting COVID-19 daily. Because the first case of COVID-19 in Nigeria was from an Italian that came into the country on February 25, 2020, this necessitates us to only run a regression model for the dataset from March 31, 2020, to April 13, 2020. The regression model for the reduced data set is available in Table 4.

From Table 4, we observed that contact and travelling history have a positive influence on COVID-19 confirmed cases as expected. Travelling history increases the chances of people being infected with COVID- 19 by $85 \%$ while contacts made by COVID-19 patience increases the tendencies of increasing COVID-19 by about $88 \%$. We conducted a robust diagnosis of the model. The $\mathrm{R}^{2}$ shows that these two variables explained about $97 \%$ of the factors responsible for COVID-19. The F-test shows that the overall model fits well to the data. According to Lukman et al. (2017), a high $\mathrm{R}^{2}$ can signal the presence of multicollinearity. Therefore, we conducted a formal test called variance inflation factor to ascertain if there is multicollinearity problem in the model (Lukman et al., 2020). According to Kibria and Lukman (2020), when the variance inflation factor (VIF) is greater than ten (10) then there is multicollinearity. However, the result in Table 4 shows that the model does not exhibit multicollinearity problem since VIF is less than 10 . We further examined if the model has an error term problem. The JarqueBera test shows that their error terms come from a normal distribution. The white test and the Durbin-Watson test shows that the error terms are not correlated and possesses constant variance. All these diagnostic checks further strengthen the fact that the performance of OLS estimator in this study is efficient. Fig. 3 shows that the predicted value and the actual values are close. From Table 5, we observed that the actual confirmed cases fall in the prediction interval. The predicted single estimates are also in agreement with the actual values except on few cases.

\section{Conclusion}

Statistical methods and the time series models have been adopted in previous studies to predict epidemic cases. The linear regression model is an essential analytical tool for prediction. In this study, we applied the linear regression model to assess the impact of travelling history and contacts on COVID-19 confirmed cases in Nigeria. The statistical model was conducted before and after the Federal government of Nigeria enforced restriction. The ordinary least squares estimator was used to estimate the parameters of the model. We carry out diagnostic checks and found out the model fitted well to the dataset. We compared the actual values with the predicted values from April 5 to April 13, 2020, and observed the predictions were very close. We found that travelling history and contacts increase people chances of being infected with COVID-19 by $85 \%$ and $88 \%$ respectively. In conclusion, the government should enforce the right policy for the containment of COVID-19.

\section{Declaration of competing interest}

The authors declare that they have no conflict of interest.

\section{References}

Adepoju, P. (2020). Nigeria responds to COVID-19; first case detected in Sub-Saharan Africa. Retrieved from https://www.nature.com/articles/d41591-02000004-2.

Al-qaness, M. A. A., Ewees, A. A., Fan, H., Aziz, A.bd El, \& El, M. A. (2020). Optimization method for forecasting confirmed cases of COVID-19 in China. Journal of Clinical Medicine, 9, 674. https://doi.org/10.3390/jcm9030674

Anastassopoulou, C., Russo, L., Tsakris, A., \& Siettos, C. (2020). Data-based analysis, modelling and forecasting of the COVID-19 outbreak. PLoS One, 15, Article e0230405. https://doi.org/10.1371/journal.pone.0230405

Ayinde, K., Lukman, A. F., Rauf, I. R., Alabi, O. O., Okon, C. E., \& Ayinde, O. E. (2020). Modeling Nigerian covid-19 cases: A comparative analysis of models and estimators. Chaos, Solitons \& Fractals, 138, Article 109911.

Ayinde, K., Lukman, A. F., Samuel, O. O., \& Ajiboye, S. A. (2018). Some new adjusted ridge estimators of linear regression model. International Journal of Civil Engineering \& Technology, 9(11), 2838-2852.

Centers for Disease Control and Prevention CDC. "How COVID-19 spreads". 2 April 2020. Archived from the original on 3 April 2020. Retrieved 3 April 2020.

Ceylan, Z. (2020). Estimation of COVID-19 prevalence in Italy, Spain, and France. The Science of the Total Environment, 729, Article 138817.

European Centre for Disease Prevention and Control. "Q \& A on COVID-19". Retrieved 30 April 2020.

Fanelli, D., \& Piazza, F. (2020). Analysis and forecast of COVID-19 spreading in China, Italy and France. Chaos, Solitons \& Fractals, 134, 1-12. https://doi.org/10. 1016/j.chaos.2020.109761

Ghosal, S., Sengupta, S., Majumder, M., \& Sinha, B. (2020). Linear Regression Analysis to predict the number of deaths in India due to SARS-CoV-2 at 6 weeks from day 0 (100 cases - March $14^{\text {th }}$ 2020). Diabetes \& Metabolic Syndrome. Clinical Research Reviews, 14, Article 311e315. 
Gujarati, D. N. (1995). Basic Econometrics. New York: McGraw-Hill.

International Health Regulations. (2020). "Statement on the second meeting of the Emergency Committee regarding the outbreak of novel coronavirus (2019nCoV)". World Health Organization. 30 January 2020. Archived from the original on 31 January 2020. Retrieved 30 January 2020.

Kibria, G. B. M., \& Lukman, A. F. (2020). A new ridge-type estimator for the linear regression model: Simulations and applications. Scientifica. https://doi.org/ $10.1155 / 2020 / 9758378$

Li, Q., Feng, W., \& Quan, Y. H. (2020). Trend and forecasting of the COVID-19 outbreak in China. Journal of Information Security, 80, 469-496. https://doi.org/ 10.1016/j.jinf.2020.02.014

Lukman, A. F., \& Ayinde, K. (2017). Review and Classifications of the ridge parameter estimation techniques. Hacettepe Journal of Mathematics and Statistics, 46(5), 953-967.

Lukman, A. F., Ayinde, K., Aladeitan, B. B., \& Rasak, B. (2020). An unbiased estimator with prior information. Arab Journal of Basic and Applied Sciences, 27(1), $45-55$.

Lukman, A. F., Ayinde, K., Binuomote, S., \& Onate, A. C. (2019). Modified ridge-type estimator to combat multicollinearity: Application to chemical data. Journal of Chemometrics, Article e3125.

Nigeria, N. C. D. C. (2020). Retrieved on 19th June, 2020 from https://ncdc.gov.ng/diseases/sitreps/?cat=14\&amp;name=An\%20update\%20of\%20COVID19\% 20outbreak\%20in\%20Nigeria.

Roda, W. C., Varughese, M. B., Han, D., \& Li, M. Y. (2020). Why is it difficult to accurately predict the COVID-19 epidemic? Infection Disease Modelling, 5 , $271-281$.

Wang, L., Li, J., Guo, S., Xie, N., Yao, L., Day, S. W., Howard, S. C., Graff, J. C., \& Gu, T. (2020). Journal of Science Total Environment. https://doi.org/10.1016/j. scitotenv.2020.138394, 138394.

Wei, W., Jiang, J., Liang, H., Gao, L., Liang, B., Huang, J., Zang, N., Liao, Y., Yu, J., Lai, J., Qin, F., Su, J., Ye, L., \& Chen, H. (2016). Application of a combined model with autoregressive integrated moving average (ARIMA) and generalized regression neural network (GRNN) in forecasting hepatitis incidence in Heng County, China. PLoS One, 11, Article e0156768. https://doi.org/10.1371/journal.pone.0156768

WHO. (2020). WHO | novel coronavirus-China. WHO. Retrieved 9 April 2020.

Wikipedia. (2020). COVID-19 pandemic in Nigeria. Retrieved on 19th June 2020 from https://en.wikipedia.org/wiki/COVID-19_pandemic_in_Nigeria.

World Health Organization. "Q and A on coronaviruses" 8 April 2020. Archived from the original on 20 January 2020. Retrieved 30 April 2020. 